\title{
Dissemination and Influence of Traditional Ethnic Wrestling in Northeast China on "Belt and Road Initiatives"
}

\author{
Gang Yin \\ College of Physical Education \\ Bohai University \\ Jinzhou, Liaoning, China
}

\author{
Tao Xu* \\ College of Physical Education \\ Bohai University \\ Jinzhou, Liaoning, China
}

\begin{abstract}
The western world has had a great influence in the process of modern sports construction. In the new era, China has proposed a development strategy of "One Belt and One Road" at various levels of economy, politics, culture and education. It has had a significant impact in more than 60 countries and regions along the route. The development of traditional national sports activities is consistent with the development of diversification in essence. The development of modern sports is a combination of the development of traditional culture and the choice of rational thinking. The development of sports culture needs to conform to the communication and interaction characteristics between different civilizations. Based on the development of traditional ethnic wrestling events in the northeast region on the "One Belt and One Road", this paper studies the spread of traditional ethnic wrestling in the Northeast China under the "Belt and Road" strategy. The development of the traditional wrestling project in Northeast China under the "Belt and Road" strategy promotes the development of traditional ethnic wrestling in the northeastern region. The aim is to provide some feasible suggestions for those who are concerned about this field.
\end{abstract}

Keywords-Northeast China; National Tradition; Wrestling Project; Belt and Road

\section{INTRODUCTION}

All walks of life have paid more and more attention to the influence of the regional ethnic traditional culture in China, especially the wrestling project of the national tradition in the Northeast, on the "Belt and Road". The "Belt and Road" strategy is a national-level top-level development strategy. It takes the opportunity of the Silk Road and the Maritime Silk Road economic belt of ancient Chinese economic and trade exchanges. Under the modern background, it has continuously strengthened exchanges and cooperation with 65 countries and regions along the line. In this process, it is of great significance to comprehensively carry forward and develop the traditional national wrestling projects in Northeast China and expand the influence of national culture on the "Belt and Road".

Phased Achievements of Humanities and Social Sciences Research of Liaoning Provincial Department of Education in 2019

\section{THE SPREAD OF THE TRADITIONAL NATIONAL WRESTLING PROJECT OF NORTHEAST CHINA UNDER THE BACKGROUND OF "BELT AND ROAD”}

\section{A. Serving the national cultural development strategy}

The "One Belt, One Road" development strategy is a strategic concept with Chinese characteristics first proposed by China in the new era according to the current international situation and the state of regional economic development. Through the development concept of advocating peaceful coexistence and sharing results, the regional economy will be realized in the new era. Win development. This strategic concept is proposed in the new era when China's economic development is relatively sluggish and the global economic development is in a recession. In order to form the synergistic development effect of the regional economy and expand China's international influence, it is a major reality in the new historical period. The development plan of meaning. Economic, political and cultural development is the main construction content of the "One Belt, One Road” strategy. Therefore, under the "One Belt, One Road" strategy, the traditional national sports wrestling project in Northeast China needs to serve the national cultural development strategy and build through the development of cultural construction. The basis of regional political mutual trust and economic prosperity, the traditional national sports wrestling project in the Northeast region enhances the cultural soft power in the field of international exchanges in China. As one of the important components of the cultural development system, sports projects can draw closer to different ethnic groups and regions through the power of sports in the new stage of development, and reduce the construction of the "Belt and Road", China and neighboring countries and regions. There are barriers between language and cultural exchanges that enhance the effectiveness of communication and cooperation $[1,2]$.

\section{B. Improving the national "Belt and Road" strategy}

Under the influence of China's "One Belt, One Road" strategy, various areas have undergone systematic deepening reforms to welcome new international friends from all over the world into the traditional culture of the Chinese nation and to conduct good cultural exchanges and interactions with China. During this period, the traditional national sports wrestling 
project in Northeast China faced both development opportunities and unprecedented challenges. In the new historical period, the traditional national sports wrestling project in Northeast China provided support and assistance from the national traditional sports culture field for the development and improvement of China's "One Belt, One Road" strategy. The "Belt and Road" strategy emphasizes the construction of an inclusive regional cultural community based on the great enrichment and prosperity of the self-culture, and the traditional national sports wrestling project in the Northeast is a good example of this. It can be seen that the "One Belt, One Road" development strategy provides a space for the development of the traditional national sports wrestling project in Northeast China. The traditional national sports wrestling project in Northeast China has promoted the enrichment and improvement of China's “One Belt, One Road” development strategy $[3,4]$.

\section{Enhancing national influence in Northeast China}

The traditional national sports wrestling project in Northeast China not only serves the overall strategy of China's "One Belt, One Road” development, but also lays a solid foundation for its own development in this process, and promotes the nationalities of Northeast China with excellent national traditional sports culture projects. Self-confidence and international influence. In the information age, the way of information dissemination and communication has been greatly changed in all walks of life. The traditional word-of-mouth and information exchange and development model of words and deeds have been difficult to keep up with the pace of social change. In the new historical period, information producers and exchangers in different countries and regions can increase the rate of information dissemination through new media and the Internet. The traditional national sports wrestling project in the Northeast can also enhance its international influence by means of new development methods in this process. Establishing a good platform for mutual trust and cooperation with countries along the route provides a historic opportunity for the development of traditional national sports wrestling projects in Northeast China.

\section{THE TRADITIONAL WRESTLING COMMUNICATION} FRAMEWORK OF NORTHEASTERN NATIONALITIES UNDER THE "BELT AND ROAD" STRATEGY

In the process of researching and analyzing the development strategy of "One Belt, One Road", the author analyzes the basic theory of communication theory and concludes that the traditional national wrestling communication framework in Northeast China mainly involves extensive development. Four aspects of communication objects, modern communication channels, enriched communication content and diversified communication subjects.

\section{A. Extensive dissemination object}

Under the "Belt and Road” strategy, China's national traditional sports culture will have wide-ranging influence in the Eurasian continent, the Indian Ocean and the Western Pacific. It will use China's radiation as a starting point and center, covering Estonian, Latvian, Lithuanian, Mongolian, and
Russian. Yemen, Egypt and Indonesia [5]. According to the research and analysis results in related fields, it can be concluded that the countries along the "Belt and Road" are very concerned about the traditional Chinese sports, especially the traditional national wrestling projects in the Northeast. At present, China’s “One Belt, One Road” development strategy divides countries along the line into a number of cooperative organizations, such as the Shanghai Cooperation Organization, the South Asian National Alliance, the Association of Southeast Asian Nations, the European Union and the Gulf Cooperation Council, the CIS Economic Union, and the Eurasian Economic Union. Actively expand the influence of traditional ethnic wrestling projects in Northeast China within the broad dissemination target.

\section{B. Modern communication channels}

If the traditional national wrestling sports activities in the Northeast region want to expand the scope of communication and enhance the influence of communication in the context of the "Belt and Road", it is necessary to use modern communication channels and material carriers to expand the internationalization in a more scientific and informational way. Influence. From the perspective of modern social culture development and dissemination, it can be concluded that the choice of sports culture communication channels directly affects whether traditional sports culture content can be directly and effectively conveyed. Modern culture and information dissemination technology provides a more modern development space for the national traditional sports wrestling project in Northeast China. In the process of the dissemination and exchange of national traditional culture in the Northeast, interactive forms, digital symbols and diversified methods can effectively enhance the ability of the national traditional wrestling sports to spread and develop [6]

\section{Enriched content}

In order to adapt to the influence of foreign culture on the development of China's national traditional sports culture, we must constantly abandon the freedom and diversity of our own culture, but need to maintain the integrity and origin of the national traditional sports culture with a positive attitude. In the development process of the national traditional wrestling project in Northeast China, there are many relatively old and backward phenomena. For example, the content of the national traditional sports project has limitations. In the international community, the traditional sports culture of the Chinese nation only knows about martial arts, qigong, tai chi, dragon dance and lion dance, and traditional wrestling for the northeastern region of China. The project knows very little about it. Therefore, in the face of this situation, China needs to use the traditional national wrestling project in the northeast region as a link in the context of the "Belt and Road" to expand the international community's understanding of traditional sports and cultural activities and sports in China, and to enhance the content of the dissemination. Sex $[7,8]$.

\section{Diversified communication subject}

Studying the traditional traditions of the national traditional sports in the Northeast region requires an analysis of the main 
body of the activities. Understand the development of the national traditional sports activities in the northeast region under the multiculturalism, as well as the main body of communication, which national traditional cultural activities have played an important role in information collection, information processing and information transmission in the "Belt and Road". However, the results of research and investigation show that under the background of the comprehensive implementation of the "One Belt, One Road" strategy, if the traditional national wrestling sports in Northeast China want to be fully developed, further expand its influence in this link, relying solely on the guidance and support of the state and the government is far from enough. In order to realize the all-round development of the traditional national wrestling project in Northeast China and enhance the influence of international communication activities, it is necessary to mobilize the support of the main actors in the social and market sectors to increase the inter-regional business contacts, international communication and social exchanges. National traditional sports projects create opportunities for development and expand the international influence of traditional ethnic sports wrestling projects in the Northeast.

\section{StRATEgiC Opinions ON PROMOTING THE}

\section{DEVELOPMENT OF TRADITIONAL WRESTLING PROJECTS IN} NORTHEAST CHINA

\section{A. Fully implement the idea of sustainable development}

1) Respect for cultural differences and cultural conflicts

To a certain extent, cultural differences and cultural conflicts can promote cultural exchanges and blend between different ethnic groups and regions. Cultural differences between different countries and regions due to differences in geographical location, historical development, and economic and political development. A diversified development trend. At present, China, including China, has reached 65 countries along the "Belt and Road" development strategy, and it has a very wide regional radiation effect. Different countries and regions along the line have different social forms, economic forms, religious beliefs, cultural history and popular trends. The countries and regions along the line have gradually developed and developed the cultural cognition and value of different ideologies under the nourishment of their respective cultures. Judge. Therefore, in the process of internationalization of the national traditional wrestling project in Northeast China, it is necessary to enhance the integration of traditional national wrestling projects in Northeast China and other countries' economic, political and cultural foundations on the basis of respecting the actual state of culture in different countries and regions. On the basis of respecting local differences, constantly adjust the communication strategies and forms of communication of traditional Chinese national sports culture, and promote the understanding and acceptance of traditional Chinese national sports culture in other cultural circles within a reasonable scope, through cultural exchanges and The collision realized the spread of the national traditional wrestling sports in Northeast China [9].

In the long-term development process, traditional wrestling sports in Northeast China have been impacted by Western foreign cultures. The people and the masses in the Northeast have paid less attention to the sports culture of the nation. The level of regional economic development has seriously restricted the local ethnic wrestling. The continued development of sports and the further expansion of influence. For example, traditional wrestling, springboards and swings in Yanbian Korean Autonomous Prefecture in northeastern China have been affected by the impact of the modern economy and modern sports. The inheritance and development of traditional national wrestling projects have been seriously affected. In the new era, under the background of the comprehensive implementation of the "One Belt, One Road" strategy, the traditional national sports project in Northeast China represented by the wrestling project has defined its own development path, actively absorbed and learned from the development experience of other national traditional sports projects, and enhanced the area. Inter-national traditional cultural exchanges and collisions, on the basis of respecting cultural differences and cultural conflicts, continue to expand their adaptability and influence $[10,11]$.

2) Enhancing cultural awareness and cultural selfconfidence

Under the circumstances that the international situation is constantly changing and the tacit understanding of regional exchanges and cooperation is constantly strengthened, the traditional national sports projects in Northeast China need to actively face the impact and influence of foreign cultures, adhere to the path of self-development, and enhance culturally

TABLE I. QUESTIONNAIRE OF THE 9TH MINORITY TRADITIONAL SPORTS WRESTLING GAMES OF YANBIAN KOREAN AUTONOMOUS PREFECTURE IN 2011

\begin{tabular}{|c|c|c|c|c|}
\hline Name & $\begin{array}{c}\text { Level } \\
\text { (kg level) }\end{array}$ & age & $\begin{array}{c}\text { Wrestling } \\
\text { qualifications (years) }\end{array}$ & Grade \\
\hline Zhehao Li & -87 & 23 & 6 & 3 \\
\hline Minkui Wu & -87 & 29 & 8 & 3 \\
\hline YongXun Han & +87 & 20 & 3 & 3 \\
\hline LongYuan Cui & +87 & 23 & 9 & 1 \\
\hline RiXing Jin & -74 & 25 & 7 & 8 \\
\hline RiZhu Zheng & -62 & 22 & 6 & 2 \\
\hline
\end{tabular}

According to the results of the wrestling project of the National Minority Sports Conference in Yanbian Korean Autonomous Prefecture in China, it can be concluded that most of the Korean traditional wrestling athletes are in the period of full development, but after the continuous follow-up survey, most athletes are participating. After a national competition, they turned to other industries to continue to develop, instead of engaging in traditional sports wrestling projects. The reason for this is not only the problems of age growth and work development prospects but also the cultural self-confidence and cultural consciousness. Therefore, in order to comprehensively enhance the influence and appeal of the traditional national sports wrestling activities in the Northeast on the "Belt and Road”, it is necessary to start from the cultural consciousness and cultural self-confidence of the nation and create protection for the sports players engaged in traditional national sports wrestling activities. The stronger development path solves the worries of professional national traditional wrestlers, enhances 
the self-confidence and consciousness of athletes and coaches for traditional ethnic sports in Northeast China, and jointly safeguards the development of national traditional culture [12, $13]$.

3) Eliminating cultural misunderstanding and cultural misinterpretation

Under the background of the "One Belt, One Road" strategy, international cultural exchanges and cultural cooperation need to reduce and eliminate the misinterpretation and misunderstanding of the traditional culture of other ethnic groups through a diversified cultural exchange platform. On the basis of the comprehensive dissemination and development of culture in Northeast China, the staff in related fields need to actively promote the construction and development of a diversified cultural exchange platform, and expand the traditional national sports through various means through the influence of mass media in the new development period. Radiation area of cultural projects. For example, through the construction of government exchanges and cooperation, business exchanges, private exchanges, and new media exchanges, and other diversified communication and communication platforms, we will open up exchange barriers between different regions and ethnic groups, and strengthen the country with the "One Belt and One Road" in a governmentled manner. "Interaction and exchanges among participants of national traditional sports and cultural activities along the line. Explore civil society and achieve cross-border cooperation. Through the forms of film, television, music, art and animation, which are popular and popular, people can realize exchanges and cooperation between different cultures and reduce misunderstanding and misinterpretation of cultures in other countries and regions. At the same time, through the network community model, the limitations of time and space can be broken, and the influence of traditional national culture in Northeast China can be expanded.

In the field of market development, we will actively guide and foster the development of traditional national sports wrestling projects in the Northeast, encourage regional markets to achieve cooperation, increase the commercial value of traditional Chinese national sports and cultural activities, and enhance the development space of commercialization. To build a platform for the commercialization of the national traditional sports culture along the "Belt and Road", and to promote economic development through cultural exchanges. Emphasis is placed on the national traditional culture that is produced and developed among different ethnic groups and regions. It is worthy of being respected. It treats the audiences in different regions with equal ability and customs, and continues to produce and disseminate the level and preference of people in different countries and regions. The traditional national sports in the Northeast region wrestle cultural goods, reducing cultural misunderstanding and cultural resentment.

\section{B. Improving the quality of traditional national sports project inheritors}

Enhance the basic qualities of the inheritors of the traditional national sports wrestling project in Northeast China, enhance the awareness of the traditional national sports wrestling project and culture in the Northeast, and promote the traditional culture of traditional ethnic sports and traditional culture. The analytical ability for project development reasons. For example, to improve the cultural protection awareness, legal awareness, economic development awareness and ideological level of the inheritors of the traditional national sports wrestling project in Northeast China, to reduce the impact of regional economic development level and basic living consumption level on personal qualities. Through cooperation with higher education institutions and sports colleges in Northeast China, we will provide more complex talents with good professional skills and solid cultural foundations for the development of regional ethnic traditional sports projects, and enhance the traditional ethnic groups in the Northeast during the process of foreign exchanges. The inheritors of the sports wrestling project understand and recognize the traditional culture of the nation. On this basis, we will actively expand the exchanges and scope of the inheritors of the traditional national sports wrestling project in Northeast China and increase the frequency of foreign exchanges. Only when the inheritance of the traditional culture of the nation and the comprehensive quality of the promoters are enhanced and the ability of foreign exchanges is enhanced, the international influence of the traditional national sports wrestling projects in the northeast region of China along the "Belt and Road" will continue to increase. With a new level of ideological cognition and development level, improve their ability to accept new things and develop new paths, and then form a driving force to change the current development of traditional national sports wrestling projects in Northeast China, under the guidance of national traditional cultural protection consciousness With its own professional knowledge and skills, it will realize the liberation of ideas and concepts, make full use of the regional economic development characteristics of different regions, actively infiltrate the national traditional culture into all other aspects of economic forms, and improve the international influence of traditional ethnic sports wrestling projects in Northeast China.

\section{Constructing multiple parties to participate in the development of national sports mechanism}

At present, according to the situation of China's economic development and cultural construction, it can be concluded that the construction and dissemination of national traditional sports culture can not only reflect the consciousness of the state and the government in political planning, but also highlight the survival of sports culture within the minority areas. And the desire to develop. It can be seen that the state and the government played a leading role in the dissemination and development of the traditional national sports wrestling project in the Northeast. By constructing a development mechanism of the traditional national sports wrestling project in the Northeast region, which is jointly participated by many parties, under the guidance of the state and the government to actively guide and make correct decisions, the overall development of social economy, politics and culture will be realized. On this basis, the traditional people of Northeast China will be established. The sports wrestling project seeks a modern development path. For example, the traditional national sports wrestling project in Northeast China originated from the daily production and labor activities of local people. In the process of the development and 
evolution of the village, changes in form and content have continued. From the perspective of historical development, it can be concluded that in the evolution of the traditional national sports wrestling project in Northeast China, there is less content recorded and disseminated in the form of words, basically based on word of mouth and limbs between the grassroots. The development of action communication and other methods. In response to this situation, the governments at all levels in the Northeast have rationally developed local sports and cultural resources under the leadership of the central government. In the "Belt and Road" , through the development of the national fitness program, the international influence of countries along the line has been expanded, and the strategic development goal of the traditional national sports wrestling project in the northeast region of China has gone global and the world has been achieved, narrowing the gap between rich and poor countries. The gap has achieved friendly exchanges and equal development among various countries, nations and regions $[14,15]$.

\section{Developing sports culture industry according to local conditions}

In the influence of the traditional national sports wrestling project in the northeast region in the countries and regions along the "Belt and Road", it is possible to integrate the traditional tourism cultural resources in Northeast China and appropriately join the traditional ethnic sports wrestling project in the Northeast. Form a multi-faceted new sports culture tourism industry. In recent years, the economic situation in the world has stabilized, the global economy has recovered, the inter-regional coordination and development capabilities have raised in an all-round way, and people's material life has been greatly satisfied. Under such developments, the people of various countries and regions are eager for a richer spiritual and cultural life, and diverse travel routes and cultural trips have become the first choice for people to experience entertainment consumption. The tourism development model based on sports culture and sports has become the preferred travel mode for internationalization in the new era. Therefore, the traditional national sports wrestling project in Northeast China can take this opportunity to actively develop a variety of sports and cultural tourism projects to attract more international friends to understand the types of traditional sports and the cultural connotation of sports. According to the survey results of China's National Tourism Administration and the State Administration of Foreign Exchange in 2015, the number of outbound tourists in China reached 120 million in 2015, and the total consumption of outbound tourism was about 250 billion US dollars, an increase of nearly $50 \%$ compared with last year. Countries along the "Belt and Road" have become the first choice for Chinese citizens to travel abroad [16, 17]. Large-scale outbound tourists have become an important way for Chinese culture to transmit outward. By enhancing the cultural awareness and cultural self-confidence of outbound tourists, it is conducive to continuously exporting the traditional culture of the Chinese nation on the way out. At the same time, actively developing the tourism resources of domestic sports culture, developing the tourism model of the farmer's characteristic tourism model and the traditional sports activities in the Northeast, can also attract international tourists to understand and feel the traditional national sports wrestling movement in the Northeast.

\section{CONCLUSION}

In summary, the traditional sports culture project in the Northeast region represented by the wrestling movement is an important manifestation of the inheritance and development of the outstanding culture of the Chinese nation. In the new historical period, China has implemented the "in the area of social production and life". "All the way" strategy, advocating the spirit of cultural exchange and cooperation. In this process, it is of great significance to comprehensively carry forward and develop the traditional national wrestling projects in Northeast China and expand the influence of national culture on the "Belt and Road". In this session, comprehensively implement the idea of sustainable development, enhance the quality of traditional national sports project inheritors, build a national sports development mechanism that participates in joint cooperation, and vigorously develop sports culture industry according to local conditions, and actively contribute to the great rejuvenation of the Chinese nation.

\section{REFERENCES}

[1] CaiLi Pei. The Development Strategy of Chinese Sports Culture from the Perspective of "One Belt, One Road"[J].sprots, vol.21, pp.138-139, 2017

[2] $\mathrm{Pu}$ Wang, Yacheng Zhu. The Value, Dilemma and Strategy of the Development of Sports Events under the Background of "One Belt, One Road"[J].Journal of Beijing Sport University, vol.07, pp.1-6, 2017.

[3] Jun Wang. Research on the development of national traditional sports based on the "Belt and Road" [D]. Shanghai University of sports, 2017.

[4] Wei Li, Ni Li. Study on the "One Belt, One Road" Strategy and the Development of National Traditional Sports Culture[J].Journal of Wushu Research, vol.04, pp.104-107, 2017.

[5] Jun Wang, Changsheng Wang, Song Gu. Study on the Construction of Minority Sports Culture Heritage Corridor under the Background of "One Belt, One Road" Strategy[J].China Sport Science and Technology, vol.04, pp.38-43, 2016.

[6] Bin Cheng, Yinlong Bai, Ping Shi. Factors and Ways Affecting the Communication of Traditional Sports Culture between China and Myanmar[J]. Contemporary Sports Science and Technology, vol.16, pp.139-140+142, 2016.

[7] Chenglei ZHAO. Analysis of the Path of Sports Culture Integration in the "One Belt, One Road" Node City-Taking Heluo Sports Culture as an Example[J].Journal of Jilin Sport University, vol.01, pp.5-8, 2016.

[8] Wenzhong Xue. Research on the Basic System of International Communication of Chinese National Traditional Sports under the "Belt and Road" Strategy[J].Journal of Nanjing Institute of Physical Education(Social Science Edition), vol.02, pp.36-40, 2017.

[9] Tongren JIANG, Lin ZHANG. Study on the Path of Development of the "One Belt, One Road" and China Sports Industry[J].Journal of Xil'an Institute of Physical Education, vol.02, pp.129-139, 2017.

[10] Peixing Tuo. The Value, Dilemma and Dissolution of Intercultural Communication of National Traditional Sports under the "Belt and Road" Strategy[J].Journal of Nanjing Institute of Physical Education(Social Science Edition), vol.01, pp.13-17, 2017.

[11] Fuxue ZHAO, Chuan-yin CHENG, Ji-ke GAO, Ling-gao LUO, Fa-wei LI. Study on Digital Protection of Unusual Minority Sports Culture Information Resources under the Background of "Belt and Road" [J].Journal of Wuhan Institute of Physical Education, vol.01, pp.5-11, 2017. 
[12] Gang CHEN. Research on Promoting International Communication of Sports Culture in the Implementation of the Strategy of "Belt and Road”[J].Journal of Capital College of Physical Education,vol.01,pp.4$7+25,2017$

[13] Fe Yui. Research on the Development of Sports Tourism in China under the Sight of "Belt and Road”[J]. Economic Research Guide, vol.02, pp.120-121, 2017.

[14] Wei JIANG, Jin QU. Research on the Development Strategy of Guangdong Coastal Sports Tourism under the Background of the Belt and Road Initiative[J].Journal of Guangzhou Physical Education Institute,vol.06,pp.61-64,2016.
[15] JunTi Qi, Lianxi Jia. Study on the development path of maritime culture and blue sports industry integration under the background of "Belt and Road”[J]. Dongyue Theory, vol.08, pp.188-192, 2016.

[16] Gang Chen. Research on the Belt and Road and the International Communication Strategy of Chinese Sports Culture[J].Sports Culture Guide,vol.07,pp.8-11+22,2016.

[17] Jun Wang, Changsheng Wang, Song Gu .Study on the Construction of Minority Sports Cultural Heritage Corridor under the Background of "One Belt, One Road" Strategy[J].China Sport Science and Technology,vol.04,pp.38-43,2016. 